\title{
The Ideal Psychiatry Training Program: A Resident's Viewpoint
}

James E. Deming, Jr., MD

UCLA

Follow this and additional works at: https://jdc.jefferson.edu/jeffjpsychiatry

Part of the Psychiatry Commons

Let us know how access to this document benefits you

\section{Recommended Citation}

Deming, Jr., MD, James E. (1987) "The Ideal Psychiatry Training Program: A Resident's Viewpoint," Jefferson Journal of Psychiatry. Vol. 5 : Iss. 2 , Article 9.

DOI: https://doi.org/10.29046/JJP.005.2.006

Available at: https://jdc.jefferson.edu/jeffjpsychiatry/vol5/iss2/9

This Article is brought to you for free and open access by the Jefferson Digital Commons. The Jefferson Digital Commons is a service of Thomas Jefferson University's Center for Teaching and Learning (CTL). The Commons is a showcase for Jefferson books and journals, peer-reviewed scholarly publications, unique historical collections from the University archives, and teaching tools. The Jefferson Digital Commons allows researchers and interested readers anywhere in the world to learn about and keep up to date with Jefferson scholarship. This article has been accepted for inclusion in Jefferson Journal of Psychiatry by an authorized administrator of the Jefferson Digital Commons. For more information, please contact: JeffersonDigitalCommons@jefferson.edu. 


\title{
The Ideal Psychiatry Training Program: A Resident's Viewpoint
}

\author{
James E. Deming, Jr., M.D.
}

\section{INTRODUCTION}

The journey between medical school graduation and specialty board certification in one's chosen field of medicine may comprise the most challenging, exciting and important times of a young professional's life. This journey is called residency education. While the most obvious objectives are cognitive education and practice in the field, trainees also face fundamental life challenges such as developing identity, intimacy and a direction for their own generative goals in the world.

Psychiatry residency should be viewed as a personal as well as professional developmental process (1). It contains all of the turbulence of adolescence revisited (2), where "normative crises" (3) can be expected to occur. This journey through fundamental stages of emotional development actually begins long before one enters residency (4), but dealing with disorders of thought, behavior and action will constitute a major challenge to the trainee's identity. Yager (5) contends that some degree of identity crisis may in fact be beneficial to growth, but that training programs should identify and control factors which magnify this crisis unnecessarily. Taintor et al (6) discussed specific stress factors and their contributions to personal and professional growth. An excellent paper by Lindy (7) presented a training director's perspective on a phase-specific model for psychiatric training based on maturational steps.

What is presented here is the trainee's perspective of a comprehensive developmental approach to residency education, addressing both program and personal issues. General principles and strategies to improve training are discussed and specific examples are offered throughout. Appendix I is a review of Psychiatry Residency Program Ideals and can, therefore, also be referred to as a summary guide to the areas discussed in the paper.

\section{PROGRAM ISSUES}

\section{Curriculum}

Training programs should concentrate on developing a comprehensive and balanced curriculum which is presented in a logical sequence by people who

Dr. Deming completed this paper while a resident at UCLA. 
are interested in and responsible about teaching. The Director of Residency Training must insist on the designation of priority didactic time in residents' work schedules which is then defended against all other intrusions, including clinical services.

While it may be true that experience is the best teacher, all newcomers to a discipline should be given the benefit of a proper introduction to their chosen field (8). This requires an overview of core knowledge, a survey of techniques and a demonstration of their utilization. Inefficient or poor planning often results in a scattered, haphazard, or incomplete curriculum, where education is squeezed in here and there, e.g., at lunch time or around clinical responsibilities.

One need only to open to the table of contents of a major psychiatry reference text such as the Comprehensive Textbook of Psychiatry (9) to have a complete curriculum mapped out. The Director and the Education Committee can adapt a sequence of course presentations and assign appropriate teachers, as their needs and resources allow. The literature contains several reviews suggesting lists of objectives for residency education, including a comprehensive "master list" offered by Enelow and Weinstein (10), among others $(7,11,12)$. Core reading lists have also been gathered and presented (13). The Psychiatry Residency Review Committee (RRC) has designated essential subject areas for curricula, some of which should supplement Table I, e.g., medical ethics, research methodology, economic/governmental issues, and ethnic/cultural considerations.

A logical approach would be to lay out a "master plan" for each year of the training program and to set aside educational time in the weekly schedules of all trainees that is as consistent as possible. This becomes a major feat when residents are "rotating away" on various clinical assignments. Here the director of training must be strongly dedicated to securing time for teaching in the face of resistance from clinical services who may "need" the residents simultaneously.

The sequence of presentations should also be guided by a logical approach (see Table I), based on the natural progression of residents' abilities and experiences. Most new trainees are insecure about their clinical skills and therefore initial priority should be given to courses which give: practice with basic techniques; knowledge of the core vocabulary; the core anatomy, physiology and pharmacology ('hard data') of the field; and guidance in the adaptation to the hospital and clinical systems of health care delivery. Later on, as finer nuances of clinical skills (e.g., the art of psychotherapy) are sharpened, dynamic insight can be applied more readily, with comfort and security in the basics. Further on, there are more fitting times to round out knowledge and exposure to the history of psychiatry, the future of the field, and research and subspecialty areas within the field.

Training programs should strive to reduce competition among varied approaches when "sides are being taken," and residents feel pressure to sort 
TABLE 1.

A Hypothetical Curriculum, Presented in Sequence, Designed to Fit Trainees' Needs Year I

Interviewing Techniques and Practice

Behavioral Assessment-Includes Mental Status Exam

Introduction to DSM III (reviewing more common disorders)

Basic Neurosciences-Review

Principles of Psychopharmacology

Inpatient Psychiatry Issues (Policies, Procedures, Allied and Ancillary Services, Milieu)

Emergency Psychiatry/Crisis (Suicide) Intervention/The Difficult (Violent, Threatening) Patient

Introduction to Psychodynamic Psychiatry

Grand Rounds-(All Residents and Faculty)

Year II

Outpatient Psychiatry Issues

Consultation-Liaison Psychiatry

Advanced Study of Psychodymamic Psychiatry

Reading Seminars-Introduction to Journal Reviews \& Critiques

Advanced Neurosciences

Advanced Psychopharmacology

Specialized Psychotherapeutic Approaches-(Couples Therapy, Behavior Therapy, Family Therapy, Group Therapy, ECT, Amytal Interview, Brief Therapy, Hypnosis, etc.)

Review of Neuro-psychological Assessments

Continued Coverage of DSM III (reviewing less common disorders)

Introduction to Child Psychiatry

Geriatric Psychiatry

Gender-Specific Psychiatry

Grand Rounds

Years III and IV

Advanced Psychiatry Readings - including trainee presentations

Advanced Child Psychiatry (including comprehensive review of development and adolescents)

Forensic Psychiatry (including court proceedings and appearances)

Further Review of Psychodynamic Readings

Review of Standard Psychiatry Text

Specialty Board Exam Review and Preparations

Psychiatry and Public Health Issues/Manpower/Administrative Psychiatry

History and Future of Psychiatry/Psychiatry Research Directions (including exposure)

Directed Special Interest Projects and Elective Experiences

Basic Teaching Skills

Grand Rounds 
themselves out prematurely as "biological" or "psychodynamic" psychiatrists. It is also a good idea to weave in some type of professional-political-social training which assists trainees in comfortably integrating and utilizing all of the help available from psychology, nursing, social work and other health care team workers. Although some of these latter objectives can be addressed in individual supervision, it may help to pay some formal attention (such as during the Inpatient Psychiatry Issues course) to ensure their successful attainment.

\section{Interpersonal Experiences}

Understanding the nature of interpersonal relations, recognizing different styles of human interactions, and learning to utilize these in our experiences with others, are quintessential skills for therapy trainees to master. This major task of residency education is often overlooked, underemphasized or left unstructured, assuming that trainees will "find their own style" somehow, even by some sort of "mental osmosis" (14).

Nemiah (15) alluded to the important distinction between other medical specialty "training" (which is built upon, and in accord with, a narrow outlook and scope taught in medical school) and Psychiatry "education" which requires broadening and growth above the narrow outlook learned in the basic medical sciences. He felt that the aspiring psychiatrist must learn a whole new way of viewing patients and illness, concerned with "experiential" aspects of human life and interaction. Such objectives, according to Nemiah, would include learning to listen, to be empathic, to follow associations, to observe feelings and reactions to patients and the character of the relationships between them and himself.

The curriculum can formally address an introduction to the recognition and use of interpersonal skills in psychotherapy, perhaps during the Interviewing or the Inpatient Issues course. The residents' clinical application of these skills must be specifically assessed by a designated "Clinical Supervisor" who can assist in improvements where needed.

Another sensitive area of an interpersonal nature deals with the assessment of the individual trainees themselves. Many trainees can benefit from individual therapy or attention to their personal concerns; at no other time in their professional lives will they be more carefully observed. A qualified "Resident's Personal Advisor," or "Advocate," in confidential conjunction with the Director of Training, should be assigned to evaluate the interpersonal skills of each trainee. Edelman (8) considers the benefits offered where personal "advisors" have no input to the "system" (of the training program).

One of the goals of learning interpersonal skills is to allow trainees to recognize and utilize different aspects of their own personalities as called for in different situations. The program can assist the trainees by outlining their specific roles at the hospital, thus guiding the nature of interpersonal relations with patients, peers, faculty, staff, etc. This fosters flexibility, instead of retreat to a passive-intellectual stereotypic character in the developing professional. It 
would also be helpful if the program could specifically designate a panel of "supervisors" for trainees which would include a "buddy," a "clinical supervisor," a "personal advisor," etc., each of whom would have a clearly defined role for the trainee (as alluded to above).

Regardless of one's cognitive abilities, the interpersonal abilities of a psychiatrist remain as the most valuable aid or tool in psychotherapy. These skills must be formally taught, specifically monitored, and improved when necessary, as trainees prepare to become the future representatives of psychiatry.

\section{Professional Indoctrination}

Education committees can do much to foster professional development during the residency training period. By defining the goals and expectations of the trainee, and establishing a plan to approach these objectives, residents will have a clear course to follow (20), as long as they are allowed to "grow up" in the program.

The training committee can introduce the concepts of professionalism by working definitions such as the following: A professional is someone who is a self-motivating, self-monitoring, disciplined, and responsible person, dedicated to upholding and furthering the standards of excellence in his or her field of work. Along with the training and experience of a professional come responsibilities: to do what is right when no one is watching, or when an easier shortcut is available; to pursue further knowledge even when one can get by without it; to exercise judgement and investigate options, but recognize the limitations of one's abilities.

Just as for other developmental tasks, the acquisition of a professional manner is a gradual, stepwise process. In this case, however, the time frame between senior medical student and senior psychiatry resident is usually only four years. Therefore, the three or four year training program should have distinct and obvious levels of progressive responsibility and authority as trainees move toward graduation. The literature addresses the differential effects of medical versus psychiatric internships on professional identity (21).

A program that leaves first year residents "on the front lines" all alone, or conversely, one that oversupervises and pampers the senior residents would not foster professional maturation. A common occurrence is for programs to stifle professional development by treating residents at all levels as subordinates. Control issues lead to stripping upper level residents of authority and responsibility, to remain under external control.

Identification with role models who have more training and experience is a vital rudiment of professional development (22). Trainees must have exposure to more learned professionals who are actually doing work via direct observation. Teaching by example is the most valuable (and ironically, one of the least used) means of fostering professional maturation. This extends itself to setting 
good examples outside of psychotherapy training, including conduct, attitude and demeanor in other daily activities.

Trainees respond better to specific examples actually demonstrated than to vague ideals verbalized (23). For instance, a sterile admonition to "start a filing system" would be more effective if the teacher could share his or her personal approach to filing and suggest other options and methods specifically. Teaching independent study skills and personal filing approaches might be included in the Journal Review Course.

Finally, each training program is surrounded by a "professional community." Residents can benefit by exposure to these professionals, especially as their judgement develops to recognize which role models they would, or would not, like to follow. In any case the training program should foster a bond with the professional community. This is discussed further in the following section.

In summary, the development of a professional attitude and behavior is another important task of residents in training. The program can foster this by review of the curriculum to see if it is consistent with progression from dependence to independence over the training years. It is also of great value to provide ample exposure to role models within the program, and opportunities to work and socialize with professionals outside the program.

\section{The Dynamics of Residency Education:}

A complex matrix of interpersonal and inter-system dynamics faces each trainee. Clarification and specificity of roles enhances more rapid adaptation and encourages resident participation in the educational system, as opposed to reluctance or ambivalence.

Figure 1 represents a schema for the system dynamics. Residents and Directors alike should scrutinize these relations and learn to recognize their collective impact on the program and on the individuals within it. In essence, herein may lie the basic elements of morale, enthusiasm and cooperation, or the reasons for apathy and dissension in a program.

The reader may begin to imagine how important each line in Figure 1 is, and will also realize that within each box lies another world of dynamics as well, such as how residents get along with each other, how faculty get along with each other, etc.

Here is a condensed summary of ideal dynamics from the two central boxes in Figure 1: residents in psychiatry are the 'junior colleagues' of the Department. They are given graduated tasks of increasing responsibility in academic and clinical assignments. First year trainees may be paternally watched over and guided. Fourth year trainees are treated as respected brothers and sisters in the profession.

The University is interested in the academics of training and opens its resources to the trainee. There should also be an active interchange and participation in medical student education, where exposure to good residents 


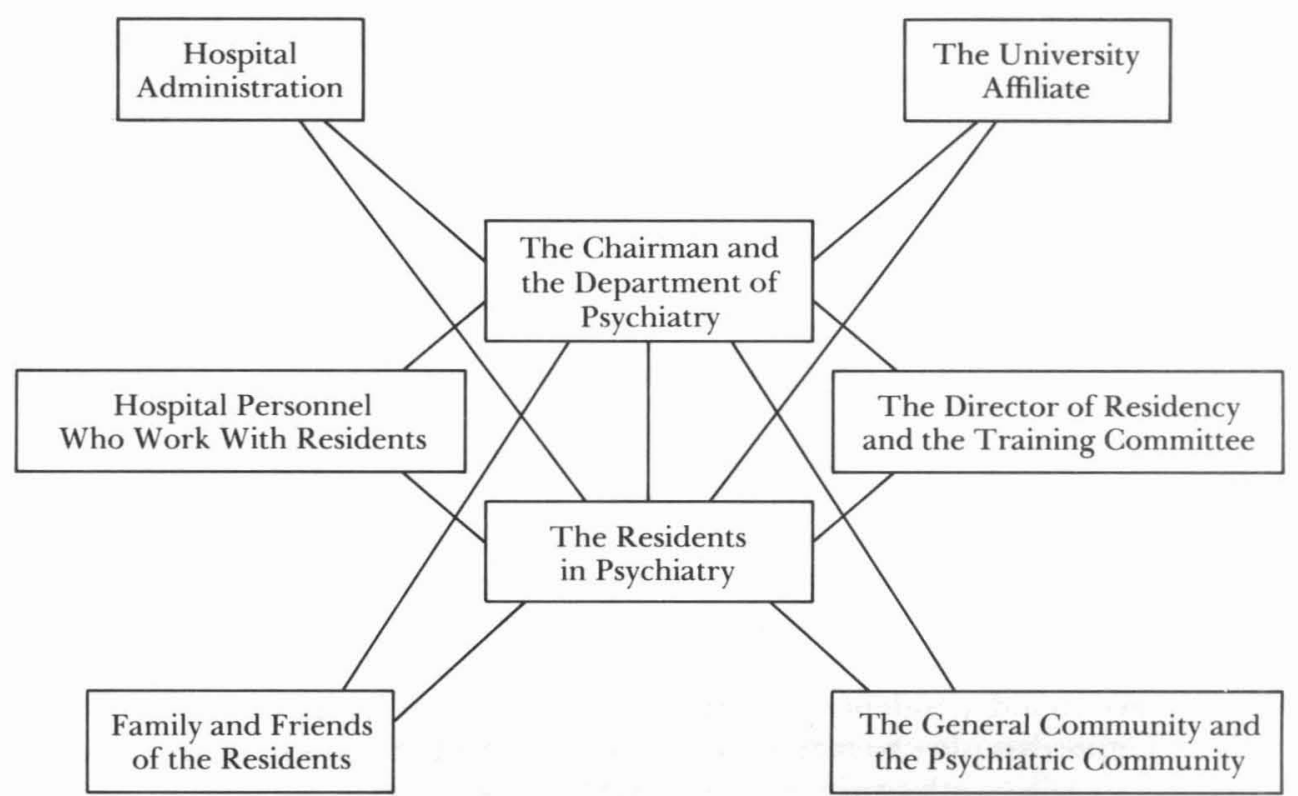

FIGURE 1.

can have significant impact in recruitment of trainees to Psychiatry, in addition to the benefit to residents of learning how to teach within the field.

The Director of Residency must be the vanguard and protector of education for the residents. He or she must be given departmental authority and control over a guaranteed pre-designated number of hours in the trainees' weekly schedule, and he or she must insist on this as a priority for the trainees. The Training Committee must then take active responsibility to organize a logical and continuously updated curriculum, administered by competent and interested teachers. The Committee should also include a designated resident representing each year of training and residents' contributions to the improvement of training must be sought and valued in committee deliberations (5). Regular monthly or weekly meetings should be arranged, as well as a comprehensive review of the program, open to all interested parties, at least once every six months.

The Chairman and the Department of Psychiatry should pay special attention to their reputation, as it will be passed on, by association, automatically to the residents in psychiatry. Reputation in the community is enhanced by public health education and public services, in which faculty and residents alike should be encouraged to participate. Residents should be introduced to local psychiatric societies early in their training. The relation between community psychiatrists and the department may be a blessing or a curse (24). Residents can serve as the common bond and foster improved relations, if allowed. 
The reputation and strength of the Department within the hospital is heavily determined by the interaction of the Chairman with the hospital administration (25). Here is a constant struggle to preserve the integrity of education for residents when service loads increase, as manpower and yearly budgets decrease. If the Chairman does not defend residents, they are doomed to abuse within the system and possible extinction at that hospital. The fact remains that service is the main factor residents exchange for their education and their salary from the hospital, yet one must keep in mind that without quality education, that salary is poor compensation for the amount of service rendered.

The Department of Psychiatry's faculty and Chairman also play a crucial role in determining the interaction with the rest of the hospital staff, including other departments. Consultation-liaison psychiatry is the key exposure of psychiatry to other departments. Examine the status and respect of the psychiatry trainees by hospital personnel within psychiatry itself. Are they integrated or removed from the "teams" on the floor? How does psychiatry relate to psychology, nursing (26), social work and other allied fields? These interactions can be rich with educational value or a source of anguish and confusion, impeding good patient care as well as education and enjoyment in the resident's work environment.

Last but not least come the family and friends of the residents. Residents begin to lead a dual life in their training years when family and friends are not invited or encouraged to become part of the training program. The Department can do much with a little effort, such as a quarterly get-together, to keep outside supporters of the residents interested in and welcomed to the program.

In summary, the many complex dynamics which affect the resident and the Department of Psychiatry are more approachable if they are delineated and attended to. When training committees follow an organized system of reviewing these dynamics, residents will be more likely to understand the role they play in this complex system. The result is a sharper focus of the residents energies, and a more efficient system of education and service for the program.

\section{RESIDENTS' PERSONAL ISSUES}

This section will focus primarily on the factors that contribute to the residents' quality of life. Approaching these ideal situations not only bolsters the morale of the residents, but inevitably improves the quality of and participation in educational and clinical experiences.

\section{The Weekly Schedule}

The ideal schedule begins with educational time as a priority (27), in fixed and regular hours each week, into which the curriculum discussed above has been carefully laid out in advance, along with assigned readings provided. 
Required clinical service hours are pencilled in next. Each division of the Psychiatry service where residents are assigned must respect the educational schedule.

As a general rule it seems that mornings are best spent on the wards or in clinics and educational hours between $11 \mathrm{a} . \mathrm{m}$. and 2 p.m. are reasonable to provide on several weekdays. However, programs must avoid the temptation to “squeeze in" education at lunch hour. This fosters resentment, places education in a secondary priority and is terribly inefficient. The ideal weekly schedule allows a full hour each day for lunch and/or a chance to compose oneself for the rest of the day.

The third consideration in weekly schedules are supervisory hours, which may be best structured toward the end of the day, especially if they are away from the main center. Supervision time must be at least two hours per week, according to RRC guidelines. The final important scheduling concern is 'open' hours wherein residents have control over what they do. This can include outpatient visits, follow-ups, phone calls, library or research work, business errands and those personal tasks which need to be addressed in the 8 a.m. to 5 p.m. business week. Residents should never have to "squeeze in" such things between a packed nine hour daily schedule of required assignments. This would certainly lead to missed lectures, skipped clinical duties and a general feeling that one's personal life is not important to the program.

Travel time and "out rotations" scheduling can disrupt the educational plan of the residents. Directors can avoid inefficient use of residents' working hours by coordinating all out rotations around a core central schedule, based on educational hours. If it serves the program best, a single "education day" or two "education half-days" each can be blocked off first, saving hours of commuting and giving residents the benefit of concentrating their attention on the educational program each week.

\section{Night Call Duty}

Though the frequency, intensity and duration of night call duty necessarily varies according to program needs, each program can still benefit by a review of their night call structures. One simple and often ignored improvement is the regularization of duty assignments, for example, every Monday and Friday for July, every Saturday for August, etc., instead of the haphazard every fourth or fifth night (regardless) type of schedule. Regularization allows predictability and stability in weekly work and in life outside work as well.

Supervision of night calls by upper level residents and faculty usually leaves much to be desired. Back-up help must be at the immediate disposal of the front-line (usually lower level) resident on call (28).

Night duty requires special technical training which does not come automatically with sheer exposure. Triage and quick screening skills, evaluative and dispositional decision making, and administrative knowledge and judgement are 
but a few of the difficulties for the new resident. Dealing with suicidal, homicidal, intoxicated, assaultive or other emergent situations should never be attempted alone by the novice. A formal course that addresses these topics and others such as techniques of crisis intervention and detection of malingering and character pathologies should be a first priority for new residents.

Knowledge in emergency psychiatry provides a sense of security but the visible presence of a recognized security officer in the emergency room is perhaps more comforting to the therapist in training. There is a high risk for the trainee to be attacked by patients; in one study the rate was $48 \%$ (29). There is no excuse for any program not providing a security agent in the emergency department whenever the trainee (male or female, strong or frail) requests. No program should dare risk the safety of its trainees while on duty, yet many still do.

The night on-call should always be reviewed immediately by conscientious, empathic educators whose intent is to teach (not scold, embarrass or harass) the resident who is going off duty. Even though time may be limited, as the resident must attend to his or her daytime duties, the morning review should never be reduced to perfunctory, empty narratives. Immense educational value can and should be derived from evaluations and decisions made during the night. Glass and Kessler (30) assert that efforts made to maximize the educational value of the on-call experience can reverse the chronic devaluation, resentment and emptiness of resident duties.

The program can also assist residents by making very clear guidelines about what specific duties and responsibilities the night duty entails. Misdirected phone calls, non-emergent demands from floor nurses and inappropriate expectations of the night residents can significantly and unnecessarily worsen the call experience.

\section{Physical Facilities}

The variation in the quality of physical facilities available to residents is more often a matter of hospital budget priorities than of hospital budget size. Any program which contends they are "unable to afford" the facilities discussed here should consider how much money they can save by simply closing their educational program altogether.

The on-call rooms are where a trainee will spend many hours during the residency years. These rooms should be secure, clean, neat, and quiet places to relax or study between work assignments. A comfortable bed, a small desk, adequate lighting, and consistent thermoregulation should be standard features. A telephone is necessary; a clock and private shower/bathroom facilities are strongly recommended.

The resident should always be provided with an office (even at out-rotation facilities), without having to share with other people on similar schedules. Offices should be readily accessible for trainees according to their clinical duties 
(inpatients, outpatients, etc.). The office should be secured so that books or notes can be safely stored. A desk with good lighting is required, as are telephones. The additional accessory of a telephone answering machine in the resident's office may be a worthwhile investment, because it allows more direct transmission of messages to the trainee, any time of day or night.

Examination rooms and interview rooms must be available to trainees in every department, including emergency, inpatient, and outpatient settings. The surest way to discourage physical exam skills and laboratory monitoring is to require special trips to facilities located elsewhere.

A library for psychiatry (if not for all medical subjects) should contain a complete and updated collection of readings. It must be immediately accessible to residents, at hours that are useful (including on-call hours). Ideally, photocopying is available at reduced cost for trainees and access to machines is immediate. Additional resources, such as videotape or audio collections are beneficial, especially when they allow trainees to listen to cassette tape subscription series which would be prohibitively expensive individually.

Audiovisual recording and playback equipment is expensive and worthwhile only where training programs teach their effective use. Residents usually are encouraged to purchase their own tape recorders. Video cameras and videotape players will become more popular as their efficacy is clarified for training programs.

The mailroom can be the ideal place for centralizing social and professional activities for the entire training program, if carefully planned. A room large enough for ten people or more to stand in, it should have extra large mailboxes arranged by training levels. This allows convenient distribution of course materials, handouts, etc. The large boxes allow residents to centralize their professional subscriptions to a stable address. A large bulletin board opposite the mailboxes becomes the central information and announcement board to be regularly checked by all.

If the mail room is adjacent to or opposite the offices for the directors of training, this fosters even more interaction with departmental secretaries and faculty, and thus the program becomes more cohesive. The kaffee klatsches and brief meetings in the mailroom can generate social, as well as educational events, for the program.

\section{Services Available to Residents}

The courtesy and helpfulness of the ward clerks and departmental secretaries is a considerable factor in the morale and functioning of the resident. As compared to the established, permanent, full-time employees of the psychiatry service, trainees are seen as transient temporary help who either get in the way with ignorance, or get out of line with new-found authority (see the earlier discussion of program dynamics).

The specific secretarial services required by residents are not extensive. 
Mail and message transmission and occasional needs for typing, notary services and so on constitute the fundamental needs. These services are as important as they are simple, and it would be helpful if programs made their availability clear. Ward clerks obviously should assist residents in conducting their clinical paperwork, not vice versa.

Therapy services are also desired or needed by trainees during the residency. Specific methods and costs of individual and/or group therapies should be elaborated. Some residents may consider personal psychoanalysis as part of their training; different programs have different arrangements available for this. An occasional or a regular process group for trainees with each other, with faculty or staff, etc., may be called for. Again each program develops its own approach to this situation. Residents should be informed of available insurance coverage for therapy, and be assured of confidentiality in all such matters.

Representation is another service which is important for trainees. Direct access to education committee meetings, to the director of training or to other specific faculty members should be able to be arranged by request. The Chief Resident or other designated resident representatives must have strong commitments to improving conditions for the training program, not just buffering the faculty-resident interactions. An anonymous suggestion box may occasionally elicit a need to address a special concern such as gender specific issues, pregnancy in the program, etc., to which the program directors should respond appropriately.

\section{Evolution of Professional Status}

Trainees who are self-respecting and diligent in their studies will notice a gradual progression in their professional self-confidence throughout the training program. This can and should be fostered rather than impeded by the residency program.

The program does have, however, an obligation to identify impaired residents. The many issues of identification, intervention and rehabilitation, and severance/re-entry must be carefully considered. In this and in all matters regarding the resident who fails to meet expected standards, the program must specify due process to be followed in regards to safeguards and appeals available to the resident facing probation or termination.

Teaching assignments should increase with experience because these reflect one's areas of acquired knowledge and skills as well as point out areas to be refined (31). Supervision of residents and medical students, along with special formal training on how to teach or speak in public should be included in the senior residents' schedule $(32,33,34,35)$.

Personal privileges should also be noticeably increased as a resident progresses toward graduation. This should include more ability to direct one's weekly schedule, to choose elective opportunities according to special interests, 
and to have admitting and directing privileges in the clinical care of one's patients.

A more liberal senior year allows the program directors to offer "autonomy under observation" as the trainee's final transition from heteronomy to autonomy. The ideal program encourages the separation "away from the nest," into private ventures for the post-graduation year to come, which is itself replete with new adjustment stresses of its own (36). By providing seniors with paging devices the program can maximize mobility while preserving availability of these residents. "Moonlighting" should be understood as an important personal and professional experience for the trainee at upper levels.

Upper level residents should also begin to participate in professional conferences and organizations. Time and funding, if possible, should be offered to trainees, in exchange for presentation of the new information to the program.

\section{Social Lives of Residents}

It is unnecessary, and perhaps unwise, for a training program to become too involved in the social lives of their residents. However, to the extent that camaraderie and morale can be improved by social functions, it is always a good idea to plan some regular social events and attempt to foster socialization indirectly as well.

Residents at all levels naturally desire to interact with one another (37). If possible, some educational programs (besides grand rounds) should include residents at different levels of training (38). The mail room, or another designated area should be set aside for residents to call their own and to mingle during their work breaks. Residents' meetings should be a weekly priority for all and the Chief Resident should make each agenda valuable and worthwhile. A residents' newsletter or other circular should be compiled weekly and posted for the program.

Residents and faculty can interact outside of the formal program in enjoyable and productive ways. Invitations to faculty homes for journal club or special discussions can be pleasant learning experiences. Many faculty have resources which residents would enjoy a chance to share once in a while such as club memberships, sporting events, hobbies, etc.

Family events offer a chance to see another side of the people one works with. These extend an invitation from the program to the people who support the trainees and faculty. An occasional picnic or outing can go a long way for a modest investment of time and energy.

Departmental events should include at least one annual meeting to air feelings about the psychiatry service and the training program, with full attendance required. Another important annual function should be the graduation banquet, where special efforts can be made to give positive reinforcement and/or token awards to all residents, not just the graduates. Certificates of recognition for excellence in clinical work, research, teaching, ward perfor- 
mance, class participation, in-training exam scores and other contributions to the program are powerful incentives for trainees.

The remaining social activities can be as broad as program creativity allows. Participation may vary but special concern should be shown to trainees who are new to the city, without local social support. Lunches are always popular with residents and often can be financially underwritten by pharmaceutical representatives. Other ideas for social events include literature/film reviews and discussion groups $(39,40)$; resident/faculty roasts or plays; "underground" newspapers; poetry, art, writing, photography displays; talent shows; hobby exhibits; name the baby picture contests; etc., etc.

\section{RECRUITMENT ISSUES (CONCERNS FOR PSYCHIATRY AS A PROFESSION)}

Having discussed the ideals for psychiatry training programs and for the individual residents, an important concern remains-How can Psychiatry recruit trainees most effectively? Many recent articles address recruitment concerns and most seem to conclude with logical recommendations that are valuable regardless of their impact on recruitment $(41,42)$. These ideas include: 1) Improving the image of Psychiatry in the public and in the medical profession (43); 2) Providing good early exposure to psychiatry and to psychiatrist role models for medical students (45); 3) Helping medical schools to select candidates with good potential to become psychiatrists; 4) Staying in touch with medical students consistently to prevent their being "snatched away" by other fields, such as Family Medicine.

I would like to offer a psychodynamic perspective on recruitment, which addresses the developmental needs of medical students. Medical students are psychodynamically similar to adolescents. The struggle for identity is paramount, and most are tiring of the perpetual student role. Non-medical peers are establishing families and careers and moving up the social ladder, while medical students can only look forward to the bottom of the totem-pole again, namely internship. The choice of a medical specialty, an entire career, can be strongly influenced by these identity issues.

Psychiatry has a vague identity itself as a profession. It is still evolving, perhaps in its own adolescence. There are many bearded, blank faces passively representing the field to medical students. Most students will not be able to tolerate such ambiguity in colleagues and in their profession, especially when they are trained to respond to facts, not feelings, and to hard data, not opinions.

Naturally, students prefer to identify with specialties that enjoy good reputations, prestige and respect, especially within their local institution. The many functions of the department of Psychiatry discussed above play key roles in dealing with the stigma of psychiatry (46). When feasible, it may be beneficial to present psychiatry training in a team effort such as a psychiatrist with an internist who can help validate the material's relevance.

Psychiatry offers the best opportunities to combine the art and science of 
medicine, but the fact remains that students want science. In fact most medical specialties can respect only the scientific aspects of psychiatry. Therefore, as a discipline, psychiatry would be more likely to attract students by presenting itself facts-first, and by sending representatives who are amicable and engaging rather than vague and indifferent with the students. Students enjoy direct exposure to psychiatrists at work (47), and may learn as much from observation as from being primary therapists (48).

Students also seek structure and predictability; thus psychiatry and its patients are often too bizarre. When students rotate through psychiatry, they usually want to know what psychiatry residents do and how they learn to make sense of the field. At this critical moment of inquiry, any resident who can produce the outline for the training program described above will surely impress the student favorably. If residents are asked to give direction to students, then psychiatry should give each resident a map.

Even though the field of psychiatry may remain a mystery to students, they should have specific facts about the training program of the psychiatric resident. After all, most students tend to consider their immediate future as much or more than their ultimate career. A well-structured psychiatry residency which addresses the educational, professional and personal concerns of the trainees will outshine most other residencies where the professions may be more "solid," but the training pathway to them is treacherous and foreboding.

Compared to other specialties, psychiatry cannot currently offer a field with technical procedures, rigorously predictable responses, immediate results or high reimbursements. Instead, psychiatry can offer an intriguing, dramatic, and challenging field that is wide open to growth and development and critically needed by society. As a career, psychiatry can offer many different lifestyles and types of practice to fit the desires of the practitioner. Finally, the study of psychiatry can be an enriching and rewarding personal experience, with many practical applications to everyday life and to understanding human beings more fully.

In summary, recruitment can be enhanced by recognizing the medical students' need to identify with a profession. Psychiatry experiences for students should be as factual and concrete as possible (with respect to the neurosciences and neuropharmacology) and presented by amicable role models who appear to "know their stuff"; to students this means they have a secure self-identity. Exposure to residents is likely to be positive if the resident can present a clear picture of what Psychiatry training is specifically about and how enjoyable and valuable it is to one's life as well as one's work.

\section{EVALUATION ISSUES}

Each program will necessarily have its own approach to evaluations of itself and its trainees. Reviewing some of the literature $(14,49,50,51,52,53)$ reveals a remarkable variety of approaches to assessing residents' performance in many 
professional and personal respects. Little is written on residents' evaluation of their teachers (54). In order to prevent these processes from becoming too complex, tedious, costly and inefficient, some basic principles of evaluation must be remembered. Appendix 1 reviews a comprehensive list of the considerations discussed previously and thus serves as a quick review of this article.

The first point to remember is never to waste time evaluating anything you would refuse to change. The program should elicit data only in so far as there is serious dedication to review and use of the data for program improvement.

A second principle of good evaluations is the intention to improve rather than label or grade current performance. This leads to the third principle of good evaluations: solicit ideas for improvement. Never invite or accept criticism which does not have constructive orientations, even though this may require reviewing narrative comments rather than computerized bubbles.

The fourth principle of good evaluations is response. For every question asked, a decision for action or a justification for inaction should be plainly offered to the participants of the evaluation. Comments that respond specifically to the suggestions of the evaluators are most important to the meaningfulness of the evaluation process.

Finally, the specification of responsibility for actions must be made clear, and those responsible must be held accountable to follow through with changes decided upon within specific deadlines. It commonly occurs that good ideas are forfeited to "someone else" who does not follow through.

The Director of Residency and the Training Committee can review each line in Appendix 1 and decide for themselves which areas of their program could be improved. A specific plan to approach each area should then be decided. It is important for program design and morale that residents participate in these changes $(5,27)$.

Evaluation of the trainee by the program is another area where the above principles must be adhered to. Considering the magnitude of the investment made in their education and their developmental needs as they approach a professional identity, trainees are understandably vulnerable and sensitive to evaluations. However, residents need and deserve the careful evaluations of their faculty and this should be via a regular, predictable and comprehensive process known clearly to all, at least twice per year. In addition, trainees should always have access to personal appointments with the director to discuss their performance. Once again, the emphasis should be placed both on recognizing positive accomplishments and on suggestions to improve areas of deficiencies. Specific plans to remedy problems and specific dates for review of such areas should be arranged. It is irresponsible for programs to give poor evaluations without plans or time for needed improvements.

Two specific evaluative methods for trainees merit attention here; these are the Psychiatry Residents In-Training Examination (PRITE) (55) and the mock orals. Under RRC requirements issued in 1986, residency programs must administer written cognitive exams (such as the PRITE) at least annually in the 
PG-2 through PG-4 years, and oral examinations of clinical skills at least twice during the four years of training. The PRITE is a comprehensive assessment of cognitive knowledge for Psychiatry. It allows a resident to see what the ABPN certifying written exam will be like, and to find out in advance which particular areas will need further study. The PRITE was not well received initially $(56,57)$, but has been continually refined and is now administered to more than $80 \%$ of residents each year (58).

Training programs can maximize use of the PRITE by organizing a formal preparatory session and a formal review session. The objectives of these sessions are: 1) to familiarize trainees with the exam style; 2) to familiarize them with the references given by PRITE; 3) to compare program and personal results for general trends, allowing a better perspective; and 4) to emphasize the positive aspects of reviewing for the exam and learning from the exam results. These sessions should not be designed as crash courses in Psychiatry.

A second specific evaluative measure which can have excellent value to trainees is the mock oral exam (simulating the oral exam for board certification in Psychiatry). This allows trainees to conduct an interview under examination, immediately review the case with discussion of differential diagnoses, decide on possible treatment courses, and then answer free form questions by the examiner. Once again, the preparation for and the review of the exam performance are of great value, as is the chance to practice and become familiar with the oral exam process. Knowing what is being evaluated, and how, allows examinees to focus energies into better performance. The faculty who participate will also benefit by directly observing their trainees at work.

These two specific evaluative measures are also the most relevant assistance to trainees interested in board certification. After all, this is an important objective for specialty training, so it should logically be included as part of such training.

\section{CONCLUDING REMARKS}

This paper has addressed most of the concerns of the trainee in psychiatry. Clinical service loads and therapy orientations at each program vary widely and no general comments as to these matters were made. Other obvious factors, such as geographical location, size of the program, etc., were also not addressed here. While it is true that diversity in psychiatric education provides balance and strength to the field, this paper asserts the need for similar fundamental developmental perspectives at all training programs.

It is unfortunate for a trainee to wander aimlessly through the critical years of his or her life spent in residency. It is tragic when training directors shirk the responsibility of organizing and orchestrating these years in order to minimize confusion, maximize education and properly orient the trainees' energies.

The future of psychiatry balances on the fulcrum of residency education. Programs that make training objectives clear and design specific pathways to 
reach them, enhance the image and the future of psychiatry and its newest colleagues.

\section{APPENDIX 1.}

\section{Residency Program Ideals}

\section{Program Issues}

A. Curriculum:

Fixed hours of residents' weekly schedules, designated as educational priority time (for coursework)

A "master plan" for the residents' education including a comprehensive curriculum

A sequence of course presentations according to the developmental levels of the trainees

The content of the courses and the teachers of the courses are continuously updated and reviewed (see evaluations)

B. Interpersonal Skills:

Teaching of their value in psychotherapy

Formal evaluation of trainee skills in psychotherapy (by a "Clinical Supervisor")

Formal evaluation of trainee skills as an individual outside therapy (by a "Personal Advisor")

Training program delineates trainee's roles in relation to patients, peers, faculty, staff, etc

C. Professional Indoctrination:

A working definition of "professional" is presented to trainees

Gradual, stepwise, recognizable pathway to professional development within the training program

Awareness of obstacles (such as control issues) which stifle professional growth

Role models within program available to teach by example

Role models in the community available to broaden trainees exposure to work and social functioning of professionals

D. Dynamics of the Training Program (see Figure 1.)

Recognition of current dynamics and their effects on the training program

Degree of concern and emphasis on improvement in the dynamics where indicated

Formal mechanism for periodic review of these dynamics and specific plans to effect necessary changes

\section{Personal Issues for Residents}

A. Weekly Schedules

Educational time as designated priority

Clinical schedules are efficient and coordinated around educational hours in the most productive fashion

A regular, guaranteed lunch time break is provided

Supervisory hours are scheduled efficiently and effectively 
Open hours are available for residents' discretion

Travel time/wasted hours are minimized

B. Night Call

Review frequency, intensity and duration

Regularize schedule to the extent possible

Availability and utility of back-up resident and faculty

Formal training in emergency psychiatry issues for entering residents

Security for trainees in emergency area

The educational vs. perfunctory use of morning report

Departmental clarification of night call duties and responsibilities

C. Physical Facilities

The on-call room (Quiet, secure, bed, desk, phone, bathroom)

Office space (Ample, accessible, phone, desk, chairs, message machines)

Exam rooms (emergency, outpatient, inpatient areas, include necessary equipment)

Library (updated, complete Psychiatry section, accessible, photocopier)

Audiovisual equipment (availability, training in its useful application)

The mail room (central address, meeting place, bulletin boards)

D. Services Available to Residents

Secretarial (courtesy, efficiency, clear availability)

Therapy (individual, process groups, analysis arrangements)

Representation (direct access to Director or Education Committee, strength of Chief Resident, anonymous input-suggestion box)

E. Evolution of Professional Status

Gradual, observable increase in rank and privilege

Teaching and public speaking assignments increase with training level

Personal privileges in clinical matters and personal schedule arrangements increase with training level

Seniors are encouraged to separate-become autonomous

Pagers, "moonlighting," private practice scouting should receive fair evaluation

Program directors avoid infantalising residents

Conference and professional meeting attendance is encouraged and supported

F. Social Lives of Residents

Program's effort to undertake and support social events

Residents' opportunities to socialize with each other (common course-work, designated meeting areas, chief resident's meetings)

Residents' opportunities to socialize with faculty/staff (special programs at faculty homes, invitations to other events with faculty/staff)

Family events for program to welcome the supporters of the program members

Departmental events (annual review of service/program; annual celebration/ awards/positive reinforcements for trainees/graduates)

Other creative social ideas in the program-quantity, quality, priority

\section{Recruitment Issues}

Image of psychiatry in the local community

Image of psychiatry in the training center 
Quality of student exposure to psychiatry service

Quantity and quality of exposure to role models for psychiatry

Psychiatry involvement in medical student admissions

Psychiatry involvement in maintaining continuous liaison with/availability to medical students throughout their training

Providing amicable teachers of psychiatry

Providing factual presentation of psychiatry practice

Providing clear and comprehensive outline of psychiatric residency education

Discussions of the positive aspects of psychiatry (career and lifestyle issues)

\section{Evaluation Issues}

Program reviews their evaluations procedures with following principles:

1) Evaluate only what is possible to make changes in

2) Evaluations emphasize potential improvement, instead of grade or label current problems

3) Evaluations solicit suggestions for improvement

4) Evaluations are seriously reviewed and responded to

5) Specific responses are generated and followed through

Director and Education Committee are responsible and thorough in complete evaluation of program and residents (see Table above)

Trainee evaluations follow well-defined protocol, at least twice per year

Trainee has access to Director to discuss performance at any time

Trainee's strengths are recognized and rewarded

Trainee's weaknesses generate specific plans for improvement and specific dates to review progress

Program maximizes benefits of Psychiatry Residents In-Training Exam and mock oral exams

\section{REFERENCES}

1. Brent DA: The residency as a developmental process. Journal of Medical Education 56(5):417-22, 1981

2. Graves JS: Becoming a psychiatrist, or Adolescence revisited. Psychiatric Annals 6(4):100-108, 1976

3. Miller DL: On becoming a psychiatrist. J Psychiatr Education 3(2):213-222, 1979

4. Moore H: Beyond physical health. Psychiatric Annals 4(10):41-50, 1974

5. Yager J: A survival guide for psychiatric residents. Arch Gen Psychiatry 30:494-500, 1974

6. Taintor Z, Morphy M, and Pearson M: Stress and growth factors in psychiatric residency training. Psychiatric Quarterly 53(3):162-169, 1981

7. Lindy J: A phase-specific model for psychiatric residency training: A training director's perspective. J Psychiatr Education 7(4):304-314, 1983

8. Edelman SE: Curriculum design and teaching techniques. Psychiatric Annals 4(10):22-37, 1974

9. Kaplan HI, Sadock BJ, Eds. Comprehensive Textbook of Psychiatry/IV. Baltimore, Williams and Wilkins, 1985

10. Enelow AJ, Weinstein HM: Goals and objectives of residency education, in The Integration of Child Psychiatry into the Basic Residency Program. Madow L, Malone CA, Eds. Hillsdale, NY, The Town House Press, 1975 
11. Bowden CL, et al: Educational objectives in psychiatric residency training: A survey of training directors and residents. Am J Psychiatry 140(10):1352-1355, 1983

12. Bowden CL, et al: Priorities in psychiatric residency training. Am J Psychiatry 137(10):1243-1246, 1980

13. Malmquist C, Soth N: A review of psychiatric literature for residency training programs, 1980's. Bulletin Medical Library Assoc. 72(3):287-294, 1984

14. Winer JA, Smilansky J, Newman J: Competency based residency training, empathy and interpretation. J Psychiatr Education 4(2):131-140, 1980

15. Nemiah JC: The idea of a psychiatric education. J Psychiatr Education 5(3):183-194, 1981

16. Goin MK, Kline F, Zimmerman W: The use of videotape in teaching supervision. J Psychiatr Education 2(2):189-196, 1978

17. Ely NE: The hidden in clinical supervision: A method to know and affect what's going on in there. J Psychiatr Education 6(2):74-86, 1982

18. Paris J: Intellectuality and emotionality in psychiatric residents. Can J Psychiatry 26(3):159-161, 1981

19. Jaynes S, et al: Clinical supervision on the initial interview-Effects on patient care. Am J Psychiatry 136(11):1454-1457, 1979

20. Griffith EE, Delgado A: On the professional socialization of black residents in psychiatry. Journal Medical Education 54(6):471-476, 1979

21. Gilmore MM, Perry SW, 3d: The psychiatry internship and the development of professional identity. Am J Psychiatry 137(10):1206-1210, 1980

22. Skodol AE, Maxmen JS: Role satisfaction among psychiatric residents. Compr Psychiatry 22(2): 174-178, 1981

23. Corradi RB, Wasman M, Gold FS: Teaching about transference: A videotape introduction. Am J Psychotherapy 34(4):564-71, 1980

24. Faulkner LR, Eaton JS, Jr.: Mental health centers and academic psychiatry departments. Am J Psychiatry 136(8):1040-1044, 1979

25. Faulkner LR, Eaton JS, Jr.: Administrative relationships between state hospitals and academic psychiatry departments. Am J Psychiatry 140(7):898-901, 1983

26. Feldman R, Cousins A, Grimaldi D: The developmental phases of the nurse/resident relationship on an inpatient psychiatry unit. Perspect Psychiatric Care 19(1):31-39, 1981

27. Leichner P, Harper D: Profile of the ideal residency program in psychiatry: The canadian resident's viewpoint. J Psychiatr Education 5(3):269-277, 1981

28. Fauman BJ: Psychiatric residency training in the management of emergencies. Psychiatry Clin North America 6(2):325-334, 1983

29. Ruben I, Wolkon G, Yamomoto J: Physical attacks on psychiatric residents by patients. J Nerv Ment Dis 168(4):243-245, 1980

30. Glass LL, Kessler DR: The on-call experience: Missed opportunities for resident education. J Psychiatr Education 4(3):213-224, 1980

31. Callen KE, Roberts JM: Psychiatric residents' attitudes towards teaching. Am J Psychiatry 137(9):1104-1106, 1980

32. Granet RB, Kalman TP, Sacks HH: From supervisee to supervisor: Aspect of the psychiatrist's training. Am J Psychiatry 137(11):1443-1446, 1980

33. Doyle BB, Baiseley E: Supervision of the resident as a teacher. Journal Medical Education 54(4):338-339, 1979

34. Findley LJ, Antczak FJ: How to prepare and present a lecture. JAMA 253(2):246, 1985 
35. Moffic HS: Educating psychiatrists to become psychiatric educators. $J$ Psychiatr Education 6(2):107-111, 1982

36. Looney JG, et al: Psychiatrists' transition from training to career: stress and mastery. Am J Psychiatry 137(1):32-36, 1980

37. Unni CS: From the realms of mysticism. Psychiatric Annals 4(10):63-75, 1974

38. Loschen EL: The resident conference: A method to enhance academic intensity. Journal Medical Education 55(3):209-210, 1980

39. Roberts JL, Steinfink DE: "Story hour psychiatry"-A fiction seminar for residents. J Psychiatr Education 4(1):43-46, 1980

40. Fritz GK, Poe RO: The role of a cinema seminar in psychiatric education. Am J Psychiatry 136(2):207-210, 1979

41. Yager J, Scheiber SC: Why psychiatry is recruiting fewer residents: The opinions of medical school deans and psychiatric department chairmen. J Psychiatr Education 5(3):258-268, 1981

42. (Various Authors) Reports from departments of psychiatry at medical schools with high recruitment into psychiatry. J Psychiatr Education 5(1):88-100, 1981

43. McNevin S, Leichner P: Factors effecting the recruitment of residents: The residents' and residency directors' view. Can J Psychiatry 28(6):449-452, 1983

44. Scully JH, Dubovsky SL, Simons RC: Undergraduate education and recruitment into psychiatry. Am J Psychiatry 140(5):573-576, 1983

45. Weintraub W, Balis GU, Donner L: Tracking: An answer to psychiatry's recruitment problem? Am J Psychiatry 139(8):1036-1039, 1982

46. Fink PJ: The enigma of stigma and its relation to psychiatric education. Psychiatric Annals 13(9):669-690, 1983

47. Neilsen AC III, Eaton JS, Jr.: Medical students' attitudes about psychiatry: Implications for psychiatric recruitment. Arch Gen Psychiatry 38:1144-1 154, 1981

48. Oldham JM, et al: Medical students' learning as primary therapists or as participant/ observers on a psychiatric clerkship. Am J Psychiatry 140(12):1615-1618, 1983

49. Langsley DG: Rating clinical skills of psychiatric residents. J Psychiatr Education $8(1): 36-42,1984$

50. Deets C, Brown M, Saslow G: Criterion-referenced objectives for a psychiatry residency program. J Psychiatr Education 3(2):162-170, 1979

51. Weinstein HM, Russell ML: Multimodal evaluation in the training of psychiatrists. $J$ Psychiatr Education 4(2):100-111, 1980

52. Drucker JJ, Klass DB, Strizich M: Supervision and the professional development of the psychiatric resident. Am J Psychiatry 135(12):1516-1519, 1978

53. Buckley P, et al: Psychotherapy skill profiles of psychiatric residents. J Nerv Ment Dis 169(11):733-737, 1981

54. Hunt DD, et al: An appraisal of methods of evaluating training in psychiatry. Journal Medical Education 15(5):332-334, 1981

55. Psychiatry Residents In-Training Examination. Available through the American College of Psychiatrists

56. Strauss GD, et al: Testing psychiatric knowledge with in-house examinations. $A m J$ Psychiatry 138(5):636-641, 1981

57. Strauss GD, Yager J, Strauss GE: Assessing assessment: The content and quality of the Psychiatry In-Training Exam. Am J Psychiatry 139(1):85-88, 1982

58. Fink PJ: Personal Communication, May, 1985

59. Tohen M, Frankenburg FR: Preparation for the certification examination. Can J Psychiatry 28(6):471-474, 1983 